\title{
THE ROLE OF WIND POWER IN ELECTRIC UTILITIES
}

\author{
HARRY DAVITIAN
}

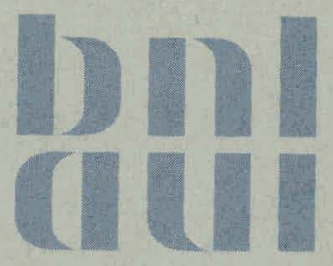

September 1977

TECHNOLOGY ASSESSMENT GROUP

NATIONAL CENTER FOR ANALYSIS OF ENERGY SYSTEMS

BROOKHAVEN NATIONAL LABORATORY

ASSOCIATED UNIVERSITIES, INC.

UNDER CONTRACT NO. EY-76-C-02-0016 WITH THE

WIND ENERGY BRANCH, SOLAR ELECTRIC DIVISION

UNITED STATES DEPARTMENT OF ENERGY 


\section{DISCLAIMER}

This report was prepared as an account of work sponsored by an agency of the United States Government. Neither the United States Government nor any agency Thereof, nor any of their employees, makes any warranty, express or implied, or assumes any legal liability or responsibility for the accuracy, completeness, or usefulness of any information, apparatus, product, or process disclosed, or represents that its use would not infringe privately owned rights. Reference herein to any specific commercial product, process, or service by trade name, trademark, manufacturer, or otherwise does not necessarily constitute or imply its endorsement, recommendation, or favoring by the United States Government or any agency thereof. The views and opinions of authors expressed herein do not necessarily state or reflect those of the United States Government or any agency thereof. 


\section{DISCLAIMER}

Portions of this document may be illegible in electronic image products. Images are produced from the best available original document. 


\title{
THE ROLE OF WIND POWER IN ELECTRIC UTILTIES
}

\author{
HARRY DAVITIAN
}

September 1977

This report was prepared as an account of work
sponsored by the United States Government. Neither the
United States nor the United States Department of
Energy, nor any of their employees, nor any of their
contractors, subcontractors, or their employees, makes
sny warranty, express or implied, or assumes any legal
liability or responsibijity for the accuracy, completeness
or usefulness of any information, apparatus, product or
process disclosed, or represents that its use would not
infringe privately owned rights.

TECHNOLOGY ASSESSMENT GROUP

NATIONAL CENTER FOR ANALYSIS OF ENERGY SYSTEMS

BROOKHAVEN NATIONAL LABORATORY UPTON, NEW YORK 1.1973 
NUIILE

This report was prepared as an account of work sponsored by the United States Government. Neither the United States nor the United States Department of Energy (DOE), nor any of their employecs, nor any of their contractors, subcontractors, or their employees, makes any warranty, express or implied, or assumes any legal liability or responsibility tor the accuracy, completeness or usetulness of any intormation, apparatus, product or process disclosed, or represents that its use would not infringe privately owned rights.

Printed in the United States of America Available from

National Technical İnformation Service

U.S. Department of Commerce 5285 Port Royal Road Springfield, VA 22161

Price: Printed Copy $\$ 4.00$; Microfiche $\$ 3.00$

December 1977

425 copies 
Current estimates suggest that the cost of wind generated power is likely to be competitive with conventionally generated power in the near future in regions of the United States with favorable winds and high costs for conventionally. generated electricity. . These preliminary estimates indicate costs of $\$ 500-700$ per installed' $\mathrm{kW}$ for mass produced wind turbines. This assessment regarding competitiveness includes the effects of the reduced reliability of wind power compared to conventional sources. Utilities employing wind power are likely to purchase more peaking capacity and less baseload capacity than they would have otherwise to provide the lowest cost reserve power.: This reserve power is needed mainly when wind outages coincide with peak loads. The monetary savings associated with this shift contribute substantially to the value of wind energy to a utility. The upper limit on the amount of electricity generated annually from wind power after a variety of wind regime and land use limitations are accounted for is rough1y $1-3 \times 10^{12} \mathrm{kWh} /$ year; i.e., about the magnitude of current electricity consumption. Factors related to utility operations, and reliability considerations in particular, will further limit the maximum likely use of wind power. 


\section{Acknowledgements}

The thoughts presented in this paper were derived in large measure from studies performed for the Wind Energy Branch of the Energy Research and Development Administration. I wish to acknowledge my debt to the staff of the Wind Branch and to many of: the researchers who participated in the studies for many informative and stimulating discussions. In addition, thanks are also due to Ed Manuel and Richard Leigh of Brookhaven National Laboratory for numerous helpful conversations.

A special thanks to Ms. Mary Lou Weis for coordinating the preparation of this document and to Miss Barbara Jean Mingino and Yvonne Oden for their patience in typing and retyping the many drafts required to produce this report. 
TABLE OF CONTENTS

$\underline{\text { Page }}$

Abstract

i ii

Acknowledgements

iv

List of Figures

$v i$

Introduction

1

Extractable Wind Power

1

Wind Machine Characteristics

2

Temporal Variations in the Wind

6

Analyzing the Economics of Wind Power

7

"Capacity Credit"

10

Some Initial Results

12

Conclusion

14

Reference

LIST OF FIGURES

Figure No. Title

Page No. Available in Various Wind Regimes 
INTRODUCTION

Recent price increases in fossi.l fuels and a growing awareness of their scarcity has led to increased interest in alternative power sources for generating electricity. Wind power has several advantages as a power source for electricity generation:

- no fuel requirements

- nonpoliuting

- relatively safe

- advanced state of knowledge regarding the engineering of aerodynamic, mechanical and electrical components of wind machines

However, the highly variable character of the power output and the large number of machines required to generate significant amounts of energy are serious obstacles to the large-scale use of wind turbines. This paper attempts to summarize several aspects of our current understanding of the potential for and the problems associated with wind power utilization by utilities.

EXTRACTABLE WIND POWER

The power that can be extracted from the wind on a practical basis is limited by a number of factors: A fundamental physical limitation on wind power use is the rate at which energy extracted from winds near the earth's surface (i.e., at heights up to the machine height) can be replenished from winds at higher levels. This limits the area density of the power extracted so that as each individual machine in an array is made greater in capacity, the optimal spacing between machines increases. The relationship between optimal spacing and machine capacity is not completely understood; current estimates are that the minimum spacing for a two dimensional array in locations experiencing isotropic wind direction distributions is about ten to fifteen rotor diameters. 
Practical considerations further limit wind power use: Terrain and availability of land to utilities limit the land areas that can be used. In addition, there are economic and technical constraints on wind machine size, rated capacity, and capacity factors. These constraints imply a lower limit on the wind velocity that can be practically exploited. When all of these factors have been accounted for, it is estimated that a maximum of some $1-3 \times 10^{12} \mathrm{kWh} /$ year of electrical energy can be extracted from the winds over the land areas of the conterminous United States ${ }^{1}$. Present total U. S. electricity consumption is about $2 \times 10^{12} \mathrm{kWh} /$ year. Thus, if wind power were exploited to its maximum potential, sufficient electrical encrgy could be generated per year to meet current electricity demand."

WIND MACHINE CHARACTERISTICS

The vast majority of wind machines built historically had power ratings in the kilowatt and subkilowatt range. From a contemporary utility perspective, considerably larger machines are necessary to reduce the overall costs of site selection, site preparation, installation, maintenance, access roads, transmission lines, protective switchgear and machine components. Although there are a multitude of machine design possibilitics (e.g., Savonious, Darrieus, vertical axis articulated blade, American farm windmill, diffuser augmented turbine) only the familiar propeller type, horizontal axis machine has proven its potential for operation in the megawatt power range. ${ }^{2}$ Wind generators deployed by utilities in the near future, and in paticular, the machines to be installed by the Department of Energy (DOE) on various utility systems, will, therefore, employ this design concept and are likely to be characterized by a two-bladed, horizontal axis rotor with a diameter of 150-300 feet, blade pitch and yaw controls,

Assuming that problems associated with dynamically matching power output to demand are ignored. 
a rotation frequency of 30-60 rpm, and a 0.2-2.0 MW rated capacity, constant speed, synchronous generator. The key factor constraining the size of these machines is expected to be blade structure technology.

Even the largest wind generators now envisioned, 1.5-3.0 MW in rated capacity, are still very small by contemporary utility standards. New coal or nuclear-fueled generators have power ratings of about $1000 \mathrm{MW}$. The simplicity of the wind generator in comparison to these huge plants is counterbalanced by the need for large numbers of machines: about 15001.5 MW units, operating at a capacity factor of roughly .35 over a year, would be needed to match the annual energy production in one such coal or nuclear plant. The protective switchgear, monitoring equipment and transmission interties required for reliable utility operation, plus land leasing or acquisition for so many machines add substantially to the basic machine cost. " In addition, power outages due to a lack of wind are more frequent than forced outages due to conventional plant breakdowns so that greater reserve requirements are likely to be needed with wind power.

A variety of mechanical to electrical power conversion schemes have been proposed for use on wind machines. These include: ${ }^{4,5}$

- DC generator with inverter

- Variable shaft speed-constant electrical frequency AC generator

- Induction generator

- Synchronous generator

* In one recent study, ${ }^{3}$ it was estimated that costs for transmission lines and protective switchgear range from about $\$ 100$ to $\$ 300$ per $\mathrm{kW}$, depending on the number of units in an array, the spacing between units, and the distance to the grid intertie. 
The primary advantage of the first two is that they are, in principle, somewhat more efficient since they permit wide variations in the speed of the rotor and thus have a higher aerodynamic to mechanical power factor. However, they are heavier and more costly than the induction and synchronous generators which require nearly constant and exactly constant speed operation respectively; the gain in efficiency may be outweighed by these and other factors. 'lhe constant speed, synchronous generator is currently favored due to a combination of beneficial features:

(1) the potential for resonant structural vibrations coupled to the low rotor frequency is minimized by having a constant rotor frequency.

(2) the generator places no reactive power demands upon the grid.

(3) it is a well known technology.

(4) weight is less than most alternative schemes.

Several machine design studies, $6,7,8$ have focussed on developing specifications for machines which minimize the cost of electricity generated. The design problem is complicated by the difficulty of estimating cost-performance characteristics of the máchine components. For example, production costs vary tremendously as a function of production quantity so that machine component costs are highly dependent on whether the total production run is 10 units or 1000 units. Design studies to date indicate that the optimized design should have a performance curve as shown in Figure 1. Below the cut-in velocity, no net power can be delivered to the grid and the machine does not operate. Above the rated velocity (corresponding to the rated capacity of the generator) blade pitch is adjusted to maintain a constant output. Typically, the cut-in velocity is roughly half the rated velocity and the rated velocity is slightly higher than the mean wind speed of the wind regime for which the machine is being designed. Although it may appear from Figure 1 that vast quantities of energy are being lost at the higher wind velocities due 


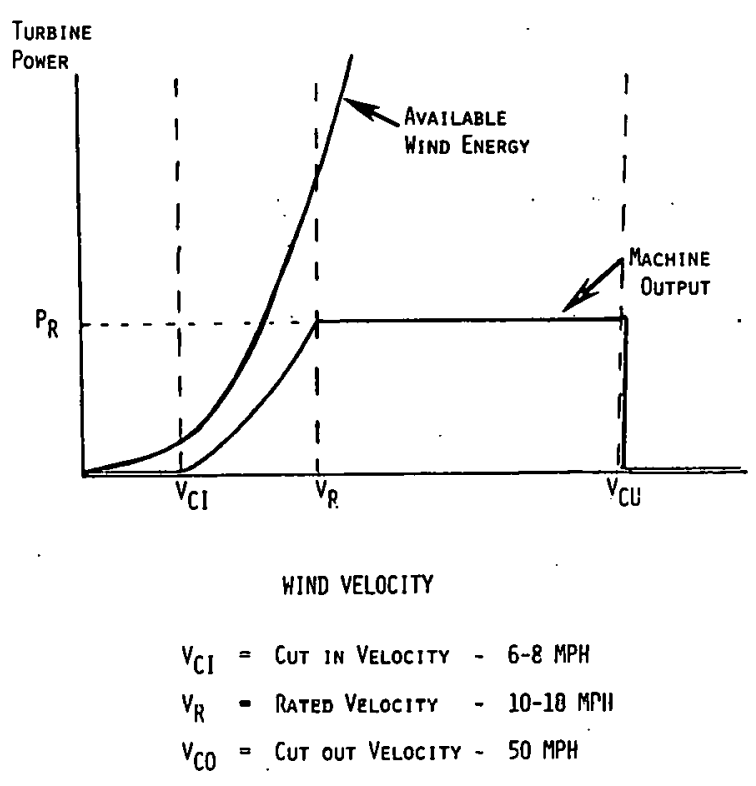

Figure 1. Characteristic machine response. 
to the plateau in the performance curve, the wind velocity frequency distribution is such that winds seldom blow at the higher velocities and a relatively small fraction of the total energy is contained in such winds. Above some velocity, the cut-out velocity, the machine is shut down to avoid damage from high winds. As an example of the results of design studies, it is estimated that a $1.5 \mathrm{MW}$ machine optimized for an $18 \mathrm{mph}$ mean wind speed would have a capacity factor of roughly .35 and would produce about $7 \times 10^{6} \mathrm{kWh}$ per year.

TEMPORAL VARIATIONS IN THE WIND

Variation in the output of wind turbines is caused by atmospheric phenomena and is manifested on several time scales of interest to utilities. Short-term variations, caused by gusting, can affect a single turbine's output; these are essentially averaged out over the spatial dimensions of even relatively small arrays. Longer-term variations are caused by meteorological factors, the diurnal cycle, and seasonal changes and will affect the output of a large array as well as single units. All fluctuations have the potential for creating problems for utility operations: subsecond time scale variations can produce network stability (synchronization) problems; second-to-minute scale variations can result in grid security (10ss-of-1oad) problems; and longer scale variations create various dispatching (scheduling of generating units) problems with consequences regarding the mix of power generating units required by the utility. The degree to which variations in power output pose difficulties for utilities is dependent on the fraction of total load being met by wind power.

These various problem areas are under study and their impact on the technical and economic feasibility of wind power use is not yet clear*. If it is determined that the potential problems

* Preliminary results from one of these studeis conducted by the General Electric Space Division presented at the Third Biennial Wind Energy Conference in Washington, D.C. (September 1977) indicate that these problems can be dealt with easily given conventional utility control and protection systems. 
associated with stability and security are serious enough to require attention, possible solutions might, for example, involve:

(1) (Stability) Ensuring that wind generators are tied into grids that are sufficiently large that they always have considerably larger power inputs from conventional generators than from wind machines.

(2) (Security) Changing spinning reserve requirements.

Characteristic averaged diurnal wind power cycles are shown in Figure 2 for low, moderate, and high wind velocity regimes. Note that in the low and moderate regimes, which contain the bulk of total available wind power, the averaged cycles show peaks that correspond roughly to daily utility load peaks. This correspondence tends to increase the value of wind energy to utilities since the highest operating cost conventional units are generally employed during the peak load periods.

ANALYZING THE ECONOMICS OF WIND POWER

An economic evaluation of wind power in a utility context involves a comparison of the total cost of wind turbines to a utility with the "value" of wind power (the total monetary savings that results from the displacement of conventional power). The determination of value requires that, besides computing the monetary savings resulting from decreased fuel consumption, additional savings that might be achieved due to changes that can be made in the purchases of conventional generating equipment must be accounted for. In general, a utility purchasing wind machine will be able to alter both the net capacity of and the type of conventional generating units that it would otherwise have purchased and experience monetary savings on both counts. These capacity related savings increase the value of wind power to utilities above the levels computed from fuel savings alone. 


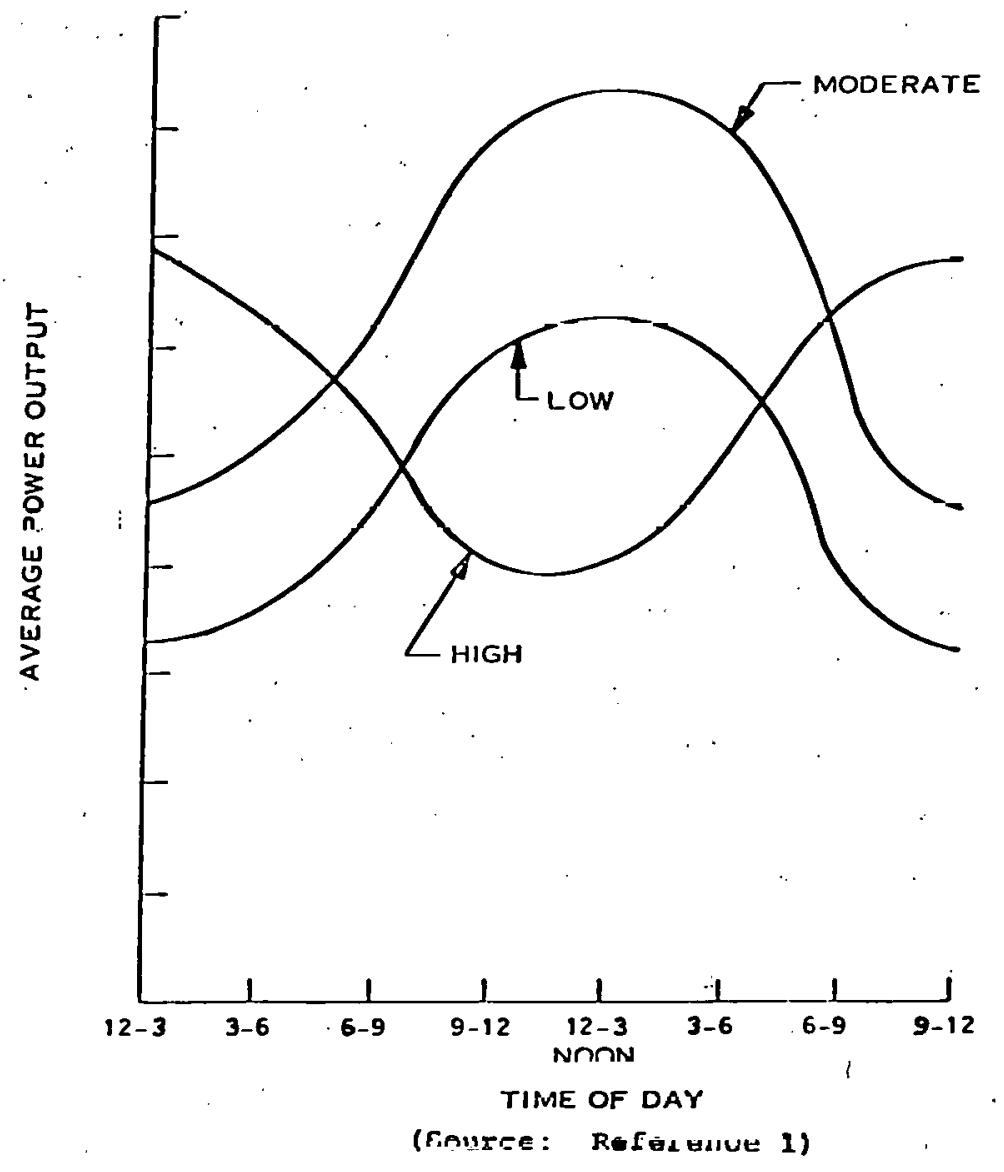

Figure 2. Diurnal cycle of averaged power available in various wind regimes. 
An analysis of the economics of the utility use of wind power requires the consideration of a variety of factors. Besides siting and machine design, which are factors common to the economics of all wind power applications, other factors specific to utilities must be considered such as reliability constraints, diurnally and seasonally varying loads, and the purchase and scheduling of a variety of alternative generating systems with different combinations of fixed and operating charges. Seemingly obvious conclusions regarding how wind generators might be employed by utilities (e.g., that a storage system would be used in conjunction with wind generators, or that wind energy would displace the most expensive conventional fuels) may, upon deeper analysis, prove to be erroneous.

The complexity of the subject is compounded by the inappropriateness of conventional utility analytical tools for studying wind power. Conventional generation planning (i.e., determining future purchases of new capital equipment) and dispatch analysis techniques assume regularities in the daily, weekly, and seasonal loads, and also assume utility control over the output of generating units except for infrequent forced outages. The major exception to these assumptions is the treatment of run-of-the-river hydropower plants, the output of which can vary with rainfall. However, the output of such hydro plants does not vary as rapidly or as frequently as would the output of a wind turbine and the total capacity of such plants is generally a small fraction of a utility's total capacity. Wind generators are a sharp departure from conventional generators in that they exhibit significant and frequent variations beyond the control of the utility.

Traditional utility analytical methods exploit the load regularities and the utility's control over conventional generating units by adopting simplifying techniques such as the use of monthly and annual load duration curves: In doing so, they do not deal 
with the chronological behavior of the system. Such methods cannot be used directly to analyze the potential role of wind generators in a utility; either they must be augmented by additional analyses which explicitly account for wind variation or, alternatively, techniques must be employed which analyze the load, conventional generation, and wind power output simultaneously and in a chronological fashion. These latter techniques have the virtue of being conceptually more straightforward, but they are cumbersome and difficult to use in practice. Studies employing both approaches are now underway under the Department of Energy and Electric Power Research Institute contracts.

"CAPACITÝ CREDIT"

Although the term "capacity credit" does not have a we11defined meaning in a power systems context, it has been used in reference to wind and solar generated electricity to refer to magnitude of the conventional equipment capacity that can be replaced by a unit of capacity from these variable sources. Often it is assumed that the credited capacity of wind power is zero; i.e., wind power is so unreliable that, for all practical purposes, no decrease in the conventional capacity otherwise needed is possible. The wind generated energy is then said to contribute as a "fuel saver" such that its contribution to the utility is measured only by the fuel not consumed when wind power is available. 6,9 The economic value of wind machines is then computed as the cost of this "saved tuel."

The "capacity credit " and "fuel saver" concepts are based on an overly simplistic view of utility operations. Their use ignores the complexities of utility systems that result from the variety of conventional generators employed, each of which has a different combination of reliability, thermal inertia, efficiency vs. load characteristic, and fixed vs. operating costs. Most importantly, the "no capacity credit" assumption ignores the fact that it is possible for a utility to save considerable monies in capital investments by purchasing peaking type generators (low 
fixed charge, high operating cost units) instead of expensive base load generators (high fixed charge, low operating cost units) while retaining the same total conventional capacity. Such a shift would make sense when combined with the purchase of wind generators if it were determined that the extra peaking type units could be used primarily to provide the needed level of system reliability while burning relatively little fuel. In this case, the total cost of wind generators would be offset by some combination of fuel and capital expenditure savings even though it was assumed that no net "capacity credit" was assigned to the wind machines. In other words, there is no direct relationship between "capacity credit" and utility economics, and it is utility economics which are ultimately of interest.

The "capacity credit" concept is troublesome because its use is an attempt to define with one number for any and all utilities what is in fact a multi-faceted characteristic that is unique to a specific utility.

Because utilities usually own and plan purchases of a variety of generating unit types, the substitution of wind power for conventional generation generally involves changes in the purchase or retirement of several different types of conventional units. Due to differences in the reliability of different types of generating units, they cannot be substituted for one another on a kilowatt for kilowatt basis while retaining a constant level of system reliability. Thus the hypothetical "capacity credit" - the net reduction in all conventional capacity due to the use of windpower will differ from one utility to another depending on previously existing equipment and the new equipment purchase schedule that would otherwise have been followed.

A computation of the economic value of wind power, based upon the wind characteristics, cost structure for conventional power generation, and reliability constraints associated with a specific utility, provides a direct, meaningful measure of the competitiveness of wind power. "Capacity credit" is a confusing detour around this central question. 
SOME INITIAL RESULTS

The results available to date regarding the economics of wind power use by utilities are general and preliminary and require elaboration by more detailed studies. Nevertheless, a few tentative conclusions have emerged that provide insights into the role wind power might play in electric power generation.

The least expensive method of incorporating wind generators into a utility network is to feed the power directly into transmission grids whenever wind power is available without the use of separate storage or back-up capacity dedicated solely for the wind array. Other generating units in the system would be constantly adjusted to meet the difference between the total load on the system and the wind array output. Thus, a greater number of generating units capable of rapid changes in output (on time scales of minutes to hours), such as gas turbines, hydropower units, or storage devices such as batteries, are likely to be needed if wind machines are employed than otherwise; large steam units, with outputs constrained to vary slowly, cannot easily provide back-up for wind generators. In addition, more peaking units are required by the utility in order to provide reserve power for periods when wind outages coincide with peak loads.

l'he availability of storage can alleviate dispatching problems arising from wind variability. However, storage and wind power are not as closely coupled as is sometimes believed. From a utility perspective, storage units are simply a method of providing peaking capacity and, as such, must compete with alternative peaking devices in any application. Storage units at each windmill, or even at each windmill array, are especially unlikely as they are prohibitively expensive; a utility investing in storage would want to use it for a variety of functions and would site the storage devices with the entire system's operation in mind.

An attractive combination of storage and wind power occurs in situations where dammed hydropower is currently being used for baseload power but, with the addition of more hydro turbine units, could be converted to peaking duty at a modest cost. In 
particular, it has been suggested that hydropower authorities in the Western United States, seeking new power sources to supply growing demand, might find wind power an attractive possibility. ${ }^{2}, 10$ An additional factor favoring this application is the advantageous tax and financing regulations governing capital investments by public power authorities which tend to make capital intensive wind power systems relatively less expensive for the authorities than for private utilities.

Another favorable application for wind power is to provide power for islands or remote communities in high wind regimes. often power in such areas is supplied by diesel or turbine plants burning expensive fuels at low efficiency. Not only is the cost of power from these plants expensive, thus rendering wind power more competetive than elsewhere, but these rapid response units provide ideal back-up power for wind systems.

As an example of some specific results, a General Electric Company study using a utility generation planning model indicates that the value of wind power varies from $\$ 200-400$ per kilowatt depending upon the region of the country and the wind regime within that region. ${ }^{1}$ These results assumed 1975 fuel and plant costs. About half of the value could be attributed to fuel savings and half to capital expenditure savings for conventional capacity with the assumed 1980's mix of generating units. By the year 2000, with a significant fraction of the mix assumed to be composed of capital intensive nuclear units, capacity related savings comprise about two-thirds of the value. A $20 \%$ increase in plant costs, and fuel escalation rates of $2 \% /$ year for coal and uranium fuel, $5 \% /$ year for 011 , and $15 \% /$ year for gas results in a value of about $\$ 700 / \mathrm{kW}$ in the Northeast United States. These latter assumptions provide a more realistic view of the value of wind power in the future.

Estimates of the production and installation costs of wind machines are very sensitive to assumptions regarding the cost of the first machine, the effects of production experience; and mass production. Most estimates range from $\$ 500-700 / \mathrm{kW}$ for the 
100 th unit produced when a $90 \%$ learning curve (cost drops by $10 \%$ for each doubling in cumulative production quantity) is assumed. Recently, the General Electric Company submitted a bid of $\$ 1,586 / \mathrm{kW}$ (in 1975 dollars) to the Energy Research and Development Administration for the second of two 1.5 MW wind machines: Based on this cost, the $90 \%$ learning curve results in just under $\$ 700 / \mathrm{kW}$ for the 100 th unit.

To date, a comprehensive analysis of the environmental costs--positive and negative--of wind power compared to conventional generating alternatives has not been made. Clearly, air and water pollution are likely to be reduced if wind power is used instead of additional conventional fuel burning power plants. At this time, the only significant negative "environmental" impacts of wind power that are known are TV and Microwave interference and "pollution" of the visual environment. If sited carefully, the latter problems can be minimized. Thus, a comprehensive comparative analysis is likely to reveal net noneconomic benefits of wind energy.

CONCLUSION

Currently available information suggests that the costs of producing and installing wind generators compare favorably with the value of such machines to utilities in some regions of the country. It is safe to assume that there will be some use of wind power by U.S. utilities starting in the next few years in areas with favorable wind regimes and high fuel costs. Islands in high wind areas and hydropower authorities in the Western U.S. are likely initial applications. The longer term potential of wind power will become more apparent as experience is gained in the production and operation of machines. 


\section{REFERENCES}

1. Wind Energy Mission Analysis, General Electric Company, Valley Forge Space Center, Rẹport \#76, SDS4267, February 1977.

2. P. C. Putnam, Power from the Wind, Van Nostrand Reinhold Company, New York, 1948 .

3. S. Linke, A. Teshome, P. D. Yehsakul, "A study of transmission and protection elements for wind energy generating systems", Brookhaven National Laboratory, December 1975 (unpublished).

4. G. E. Jorgensen, M. Lotker, R. C. Meier, D. Brierly, Design, "Economic and System Considerations of Large Wind-Driven Generators", IEEE Power Engineering Society, Winter Meeting, January 1976.

5. T. S. Jayadev, "Windmills Stage a Comeback", IEEE Spectrum, November 1976, p. 45.

6. Wind Energy Mission Analysis, Lockheed California Company, Report \#LR27611, September 1976.

7. Design Study of Wind Turbines $50 \mathrm{~kW}$ to $3,000 \mathrm{~kW}$ for Electric Utility Applications, General Electric Company, Valley Forge Space Center, ERDA/NASA-19403-76/2, February 1976.

8. Design Study of Wind Turbines $50 \mathrm{~kW}$ to $3,000 \mathrm{~kW}$ for Electric Utility Applications, Kaman Aerospace Corporation, ERDA/NASA$19404-76 / 2$, February 1976.

9. Operational, Cost and Technical Study of Large Wind Power Systems Integrated with an Existing Electrical Utility, Southwest Research Institute, 1976.

10. C. J. Todd, P. L. Eddy, R. C. James, W. E. Howe11, "CostEffective Electrical Power Generation from the Wind" Proceedings of the 1977 Annual Meeting, American Section International Solar Energy. Society. 